Original Research Article

\title{
Effect of Withania somnifera on physical and cardiovascular performance induced by physical stress in healthy human volunteers
}

\author{
Tripathi RK ${ }^{1}$, Salve BA ${ }^{2}$, Petare $\mathrm{AU}^{1} *$, Raut $\mathrm{AA}^{3}$, Rege $\mathrm{NN}^{1}$
}

${ }^{1}$ Department of Pharmacology and Therapeutics, College building, 1st floor, Seth GS Medical College and KEM Hospital, Parel, Mumbai 400 012, Maharashtra, India ${ }^{2}$ Diabetes Consultant, Dr Bharat Salve Diabetes Clinic Ahmednagar, Maharashtra, India

${ }^{3}$ Department of Clinical Research and Integrative Medicine, Kasturba Health Society, Medical Research Centre, Mumbai, Maharashtra, India

Received: 27 August 2016

Revised: 07 September 2016

Accepted: 28 September 2016

*Correspondence to:

Dr. Petare AU,

Email: anuppetare@gmail.com

Copyright: (C) the author(s), publisher and licensee Medip Academy. This is an openaccess article distributed under the terms of the Creative Commons Attribution NonCommercial License, which permits unrestricted noncommercial use, distribution, and reproduction in any medium, provided the original work is properly cited.

\begin{abstract}
Background: Withania somnifera (WS) rejuvenates, increases vigour, vitality and immunity. The antistress effects of WS on physical performance and cardiovascular parameters during exercise were evaluated in healthy volunteers. Methods: Prospective, open label, randomized, placebo controlled, comparative, pilot study was designed in healthy adult volunteers. After Ethics committee approval 30 consented participants were randomly assigned into three equal groups to receive single capsule for 28 days containing maize starch (placebo group), WS aqueous extract 330mg (WS 330 gr) and 500mg (WS 500 gr). They were assessed at day 0, day 14, day 28 with physical stressors (six minute exercise test, YMCA Submaximal Test, Fixed workload exercise on cycle ergometer), Jammers' hand held dynamometer test and cold pressor test in each visit. Physical performance was evaluated as maximum distance, speed, oxygen consumption, hand grip strength. Cardiovascular response was assessed by heart rate and blood pressure measurements.

Results: On day 28, both WS 330 and WS 500 groups showed significant increase in mean distance travelled and average speed compared to placebo $(\mathrm{p}<0.005)$. WS 330 and 500 groups showed significant decrease in mean systolic BP on fixed workload exercise, compared to placebo $(\mathrm{p}<0.05)$.

Conclusions: WS increased physical performance when participants were subjected to physical stress but it did not increase the activity of sympathetic system thus contributing to its anti-stress activity.
\end{abstract}

Keywords: Antistress, Cycle ergometer, Cold pressor test, $\mathrm{VO}_{2} \max$

\section{INTRODUCTION}

Stress is a biological response to physical or emotional stimulus which is controlled by the brain. ${ }^{1}$ Any agent or events that threaten homeostasis or causes stress are called as stressors. Exposure of stressor in an individual results in a physiological compensatory response launched by the body, i.e. activation of sympathetic nervous system and release of cortisol, epinephrine and nor-epinephrine from adrenal medulla via hypothalamicpituitary-adrenal axis. ${ }^{2}$ Different individuals' manifest this compensatory mechanism as emotional, behavioural, and even physical symptoms which may vary enormously on prolonged exposure to stressors.

Pathogenesis of hypertension, stroke, ulcers, coronary heart diseases, decreased immunity, metabolic disorders, and mental imbalance leading to anxiety and depression 
are implicated by such kind of excessive or defective compensatory mechanisms when subjected to stressors on chronic basis. ${ }^{3-5}$ Currently in modern medicine, drugs which can modulate the compensatory mechanism to stress and with minimal adverse effects are not available.

The herb Withania somnifera (WS) has been used in Ayurveda (the Traditional System of Medicine in India) since long for its Rasayana properties to increase the vigour, vitality and immunity. In healthy individuals it is not only found to be safe on hematological and biochemical organ function tests but also it has muscle strengthening and lipid lowering action. ${ }^{6}$ In this study we evaluated the effect of WS aqueous extract on physical performance and sympathetic activity in healthy participants when subjected to physical stress.

\section{METHODS}

This was an academic (non-sponsored) pilot study designed as prospective, open label, randomized, placebo controlled and comparative study in healthy adult volunteers with fixed dosage regimen. The study was conducted after the permission of Institutional Ethics Committee. Study has been registered at CTRI with acknowledgement Number REF/2015/10/010044.As mentioned in standard literature; therapeutic dose range of Withania somnifera is 3-6 gm of crude pulverized roots. Two doses of the herb were selected to span the above mentioned therapeutic range. Withania somnifera in dose of $330 \mathrm{mg}$ and $500 \mathrm{mg}$ aqueous extract in powder form were studied, which were equivalent to $4 \mathrm{gm}$ and 6 gm of crude pulverized roots of Withania somnifera (Ashwagandha) respectively. The participants were randomized into three groups of 10 each as placebo, WS330 and WS500 group. WS330 and WS500 group received $330 \mathrm{mg}$ and $500 \mathrm{mg}$ respectively of WS aqueous extract in the capsule form once daily in the morning for 28 days, while the placebo group received the maize starch capsule at the same dosage frequency. Standardized aqueous extracts from the roots of Withania somnifera were procured from Shri Kartikeya Pharma, Ixoreal Biomed Private limited, Abids, HyderabadAndhra Pradesh as a gift sample with the certificate of analysis and the capsuling and packaging of these powder form extracts was done by a Shivangi Pharmaceuticals, Mumbai.

Male participants between the age of 18-45 years and BMI between $18.5 \mathrm{~kg} / \mathrm{m}^{2}$ and $24.9 \mathrm{~kg} / \mathrm{m}^{2}$ were selected for the study and the written informed consent was obtained. The participants were screened for their healthy status from clinical history, physical examination, blood examination, chest radiography and ECG and eligible participants were randomized into one of the three groups. The evaluation consisted of three visits viz. baseline, day 14 and day 28 . The study medication was dispensed after the baseline visit evaluation. At each visit after 20 minutes of initial rest to assess effect on physical performance participant was asked to perform a) $6 \mathrm{~min}$ cycle ergometer exercise with fixed resistance and no speed limit. $^{7-10}$ After 20 min the hand grip strength was assessed by b) Jammers hand held dynamometer average of 3 readings was taken with 1 minute gap in between each reading. ${ }^{10,11}$ Following this c) YMCA cycle ergometer submaximal test was performed with 3-4 increasing workload $(25,75,100,125$ Watt workload) for 9-12 minutes after each of these test participant was instructed to rest for 20 min. ${ }^{12,13}$

Then to assess effect on sympathetic nervous system d) Fixed workload exercise on cycle ergometer test was performed for $6 \mathrm{~min}$ with fixed speed of $50 \mathrm{rpm}$ and resistance of 75 Watt after 20 min rest ${ }^{12,14}$ and e) Cold pressor test where in participants were asked to immerse hand in $0-1{ }^{\circ} \mathrm{C}$ water bath for 3 min. ${ }^{15}$ The whole procedure took 4-5 hrs. Variables assessed in these tests during study procedure are mentioned in Table 1.

All tests and exercises were done in temperature range of $24-26^{\circ} \mathrm{C}$ (ambient temperature) during $9 \mathrm{AM}$ to $1 \mathrm{PM}$ in an air conditioned room. The participants were instructed to fast for at least 1 hour before testing, and were asked to refrain from ingesting beverages containing caffeine.

\section{Statistical analysis}

Formal sample size calculation was not done as it was a pilot study. Repeated measure of ANOVA was used for the within group analysis of all the variables from baseline visit to visit 1 (day 14) and visit 2 (day 28). Post hoc Tukey test was applied when repeated measures of ANOVA showed significant difference of $p<0.05$. For comparison of all the variables, between placebo group and each study group at each visit, unpaired t-test was used. Similarly, lower dose of each study drug was compared with the higher dose of the same study drug by using unpaired t-test.

\section{RESULTS}

\section{Table 1: Variables assessed in healthy volunteers during the different exercise protocols.}

\begin{tabular}{|ll|}
\hline Exercise/Test & Variables assessed \\
\hline $\begin{array}{l}\text { Six minute cycle } \\
\text { ergometer exercise test: }\end{array}$ & $\begin{array}{l}\text { Distance travelled, } \\
\text { Average speed }\end{array}$ \\
\hline $\begin{array}{l}\text { Hand grip strength by } \\
\text { Jammers' hand held } \\
\text { dynamometer }\end{array}$ & Muscle power (kilogram) \\
\hline $\begin{array}{l}\text { The YMCA Cycle } \\
\text { Ergometer Submaximal } \\
\text { Test }\end{array}$ & $\begin{array}{l}\text { Maximum oxygen } \\
\text { consumption (VO2max) }\end{array}$ \\
\hline $\begin{array}{l}\text { Fixed workload exercise } \\
\text { on cycle ergometer }\end{array}$ & $\begin{array}{l}\text { Systolic and Diastolic } \\
\text { BP, Heart Rate, }\end{array}$ \\
\hline Cold pressor test & Systolic and Diastolic \\
\end{tabular}


A total of 38 participants were screened out of which 7 did not meet the inclusion and exclusion criteria and one participant was dropped out from placebo group due to inability to follow up. Mean age of the 30 volunteers was $27.37 \pm 2.48$ years (Range: $22-36$ ). The mean height was $170.73 \pm 6.77 \mathrm{Cm}$ (Range: 158 - 186). The mean weight was $67.00 \pm 7.21 \mathrm{Kg}$ (Range: $52-81$ ). The mean body mass index was $22.92 \pm 1.44 \mathrm{Kg} / \mathrm{m} 2$ (Range: 19.37
- 24.7). The general and clinical examinations of all the volunteers were normal. All volunteers were nonsmokers, non-drinkers, and non- tobacco chewers. The chest X-ray PA view and 12 lead ECG of all the volunteers were normal. All volunteers were HIV and HBsAg negative. The laboratory values of all the included participants were in normal range.

Table 2: Effect on physical performance of healthy volunteers on exposure to physical stress.

\begin{tabular}{|c|c|c|c|c|c|}
\hline & $\begin{array}{l}\text { Placebo } \\
\text { Day } 0\end{array}$ & $\begin{array}{l}\text { Placebo } \\
\text { Day } 14\end{array}$ & $\begin{array}{l}\text { Placebo } \\
\text { Day } 28\end{array}$ & $\begin{array}{l}\text { WS } 330 \\
\text { Day } 0\end{array}$ & $\begin{array}{l}\text { WS } 330 \\
\text { Day } 14\end{array}$ \\
\hline $\begin{array}{l}\text { Maximum distance } \\
\text { travelled in } \mathbf{K m}\end{array}$ & $3.26 \pm 0.42$ & $3.292 \pm 0.39$ & $3.352 \pm 0.41 *$ & $3.223 \pm 0.32$ & $3.585 \pm 0.263^{*}$ \\
\hline $\begin{array}{l}\text { Maximum speed } \\
\text { reached in } \mathrm{Km} / \mathrm{hour}\end{array}$ & $\begin{array}{l}43.983 \pm \\
2.36\end{array}$ & $44.800 \pm 2.46$ & $44.588 \pm 2.19$ & $43.633 \pm 5.628$ & $45.603 \pm 4.588$ \\
\hline $\begin{array}{l}\text { Average speed } \\
\text { reached in } \mathrm{Km} / \text { hour }\end{array}$ & $\begin{array}{l}32.733 \pm \\
4.08\end{array}$ & $33.08 \pm 3.84$ & $33.68 \pm 4.03 *$ & $32.3 \pm 3.12$ & $35.98 \pm 2.66^{*}$ \\
\hline $\begin{array}{l}\text { Hand grip strength } \\
\text { (Muscle power in } \\
\text { Kilogram force) }\end{array}$ & $\begin{array}{l}40.77 \pm \\
5.84\end{array}$ & $41.04 \pm 5.69$ & $40.98 \pm 5.62$ & $42.82 \pm 5.86$ & $43.99 \pm 5.70^{*}$ \\
\hline $\begin{array}{l}\text { YMCA Cycle } \\
\text { ergometer } \\
\text { submaximal test } \\
\text { (VO2 max in } \\
\mathrm{mL} / \mathrm{kg} / \mathrm{min})\end{array}$ & $34.2 \pm 1.61$ & $34.42 \pm 1.47$ & $34.55 \pm 1.63$ & $33.55 \pm 1.10$ & $34.63 \pm 1.54^{*}$ \\
\hline
\end{tabular}

On post Tukey test: ${ }^{*} \mathrm{p}<0.05$ compared to baseline visit; ${ }^{\#} \mathrm{p}<0.05$ compare to visit 1

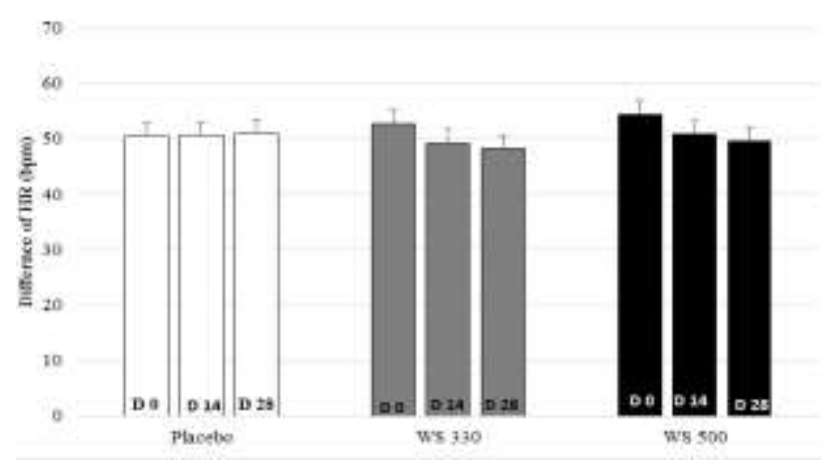

Data are expressed as Mean $\pm \mathrm{SD}$.

Figure 1: Comparative effect of Withania Somnifera (WS) on difference of heart rate (before and during) in fixed workload exercise.

The effect on physical performance is shown in Table 2 for placebo, WS330 and WS500 groups respectively. In placebo group, on day 28 the mean distance travelled increased significantly to $3.352 \mathrm{~km}$ (Baseline $=3.26 \mathrm{Km}$, $\mathrm{P}=0.0275)$ and mean average speed increased to 33.683 $\mathrm{km} / \mathrm{hr}$ (Baseline $=32.733 \mathrm{Km} / \mathrm{hr}, \mathrm{P}=0.0089$ ) while maximum speed, hand grip strength and $\mathrm{VO}_{2} \max$ were comparable.
In WS 330 Group on day 28 the mean distance travelled increased to $3.73 \mathrm{Km}$ (Baseline $=3.223 \mathrm{Km}, \mathrm{P}=$ $<0.0001$ ), mean maximum speed increased to 47.732 $\mathrm{km} / \mathrm{hr}$ (Baseline $=43.633 \mathrm{Km} / \mathrm{hr}, \mathrm{P}=0.008)$, and mean average speed increased to $37.457 \mathrm{~km} / \mathrm{hr}$ (Baseline = $32.3, \mathrm{P}=<0.0001)$. Similarly, on day 28 mean $\mathrm{VO}_{2} \max$ was increased to $35.363 \mathrm{~mL} / \mathrm{kg} / \mathrm{min}$ (Baseline $=33.552$ $\mathrm{mL} / \mathrm{kg} / \mathrm{min}, \quad \mathrm{P}=<0.0001)$ and hand grip strength increased to $44.943 \mathrm{Kg}$ (Baseline $=42.827 \mathrm{Kg}, \mathrm{P}=$ 0.0002).

In WS500 group on day 28 the mean distance travelled increased to $3.722 \mathrm{Km}$ (Baseline $=3.21 \mathrm{Km}, \mathrm{P}=0.0003$ ), mean maximum speed increased to $47.437 \mathrm{Km} / \mathrm{hr}$ (Baseline $=42.347 \mathrm{Km} / \mathrm{hr}, \mathrm{P}=0.0016)$, and mean average speed increased to $37.383 \mathrm{Km} / \mathrm{hr}$ (Baseline $=32.167$ $\mathrm{Km} / \mathrm{hr}, \mathrm{P}=0.0002)$. Similarly, on day 28 mean VO2max was increased to $35.625 \mathrm{~mL} / \mathrm{kg} / \mathrm{min}$ (Baseline $=33.578$ $\mathrm{mL} / \mathrm{kg} / \mathrm{min}, \quad \mathrm{P}=<0.0001)$ and hand grip strength increased to $41.362 \mathrm{Kg}$ (Baseline $=39.418 \mathrm{Kg}, \mathrm{P}=$ $<0.0001)$.

On day 14, WS 500 dose showed significant increase in mean distance travelled and mean average speed on six minute cycle ergometer exercise test, compared to placebo. Similarly on day 28 , both WS 330 and WS 500 doses showed significant increase in mean distance 
travelled and mean average speed compared to placebo. Mean maximum speed, hand grip strength and VO2max were comparable to placebo. But there was increasing trend in hand grip strength and VO2max of WS 330 and WS 500 doses; which was absent in placebo group. There was no significant increasing dose effect present in any physical performance variable at day 14 and day 28 between WS330 and WS500 groups.

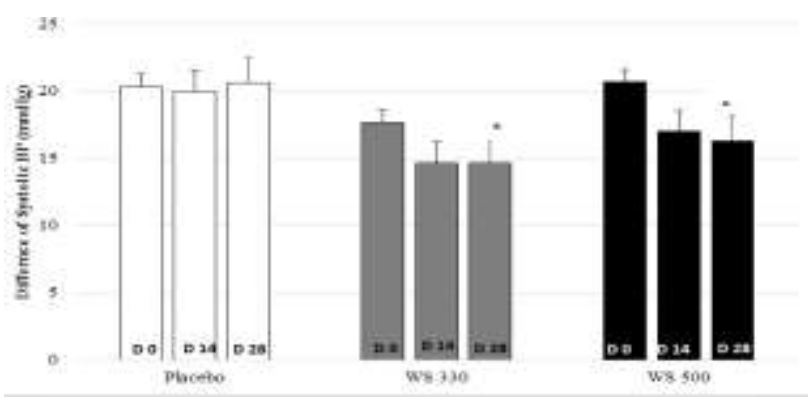

Data are expressed as Mean $\pm \mathrm{SD},{ }^{*} \mathrm{p}<0.05$ using unpaired $t$ test vs. Placebo at respective visit.

Figure 2: Comparative effect of Withania somnifera (WS) on difference of systolic BP (before and during) in fixed workload exercise.

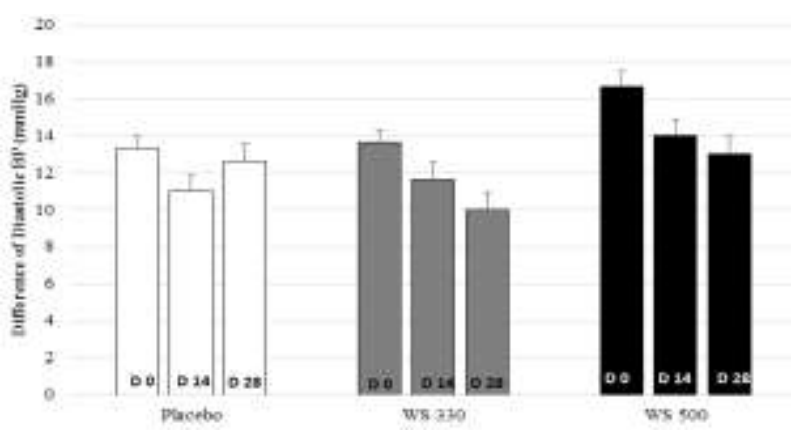

Data are expressed as Mean \pm SD.

Figure 3: Comparative effect of Withania somnifera (WS) on difference of diastolic BP (before and during) in fixed workload exercise.

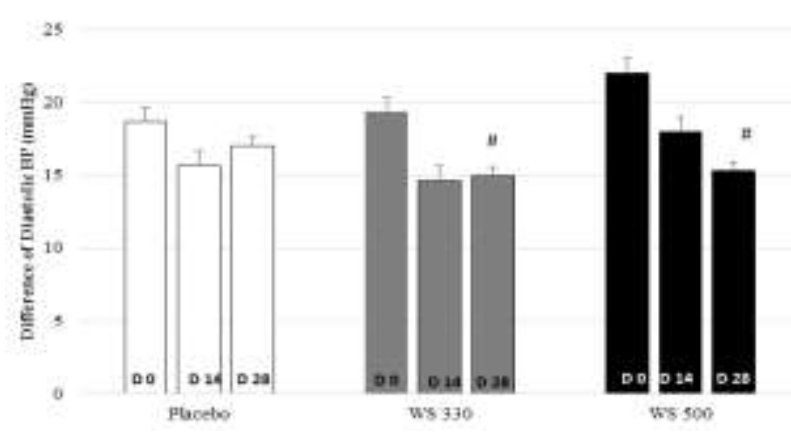

Data are expressed as Mean $\pm \mathrm{SD}$. \# $\mathrm{p}<0.05$ using paired t test, WS330 day 28 vs baseline. WS 500, day 28 vs baseline.

Figure 4: Comparative effect of Withania somnifera (WS) on difference of diastolic BP (before and during) in Cold Pressor test.
Effect on sympathetic system: In all the three groups, on day 14 and day 28; Difference of systolic, diastolic BP and heart rate before and during fixed workload exercise were recorded.

In fixed workload exercise test as well as in cold pressor test WS 330 and WS 500 groups did show a decreasing trend in the heart rate but when compared to its baseline (day 0 ) or placebo day 28 no statistical significance was detected (refer figure 1)

In fixed workload exercise test WS 330 and WS 500 groups did show a decreasing trend in the systolic BP but when compared to its baseline (day 0) no statistical significance was detected. When systolic BP readings in fixed workload test were compared with day 28 of placebo both WS 330 and WS 500 showed statistical decrease $(\mathrm{p}<0.05)$ in systolic blood pressure. There was no statistical difference between day 28 readings of systolic BP in WS 330 and WS $500 \mathrm{mg}$ (refer figure 2). However in cold pressor test WS 330 and WS 500 groups did show a decreasing trend in the systolic blood pressure but when compared to its baseline (day 0) or placebo day 28 no statistical significance was detected.

In fixed workload exercise test WS 330 and WS 500 groups did show a decreasing trend in the diastolic blood pressure but when compared to its baseline (day 0 ) or placebo day 28 no statistical significance was detected (refer figure 3). But in cold pressor test WS 330 and WS 500 groups did show a statistical reduction $(\mathrm{p}<0.05)$ in the diastolic BP when compared to its baseline (day 0). When diastolic BP readings were compared with day 28 of placebo both WS 330 and WS 500 showed no statistical significant decrease in diastolic blood pressure (refer figure 4). There was no statistical difference between day 28 readings of systolic BP in WS 330 and WS $500 \mathrm{mg}$.

\section{DISCUSSION}

Everyday activity is perceived by the brain as a stress. ${ }^{1,3,5}$ Current management of stress include behavioral therapy and relaxation exercises, SSRI and antianxiety drugs for psychosomatic disorders however no drugs are given prophylactically to cope up with stress and prevent its long term complications. Hence the adaptogenic/antistress activity of Withania somnifera was evaluated in terms of physical performance and the effect on sympathetic nervous system (cardiovascular parameters) was assessed in presence of physical stress. The study was conducted on healthy adult volunteers to avoid the confounding effect of diseases and physical deformity. In addition the present study was planned to evaluate the prophylactic use of the herbal drug in healthy individuals as adaptogen/antistress agent. As per the present study objective Withania somnifera was compared with placebo and lower dose was compared with the higher dose of respective herb to evaluate incremental dose effect. 
The present study was conducted for 4 weeks because, Sandhu et al in 2010 observed the significant increase in physical performance after 8 weeks of Withania somnifera administration in healthy volunteers and in that study no effect of Withania somnifera was evaluated in between day 0 to week $8 .^{6}$ So we decided to evaluate the effect of the Withania somnifera on physical performance and sympathetic nervous system (Cardiovascular parameters) during and at the end of 4 weeks of drug administration. We also evaluated the effect of the study drugs after baseline visit on day 0, on day 14 and day 28 i.e. last visit (Day 28). Day 14 visit was kept to see if the effect can be observed early also.

In the present study Withania somnifera when administered in dose of $330 \mathrm{mg}$ to healthy volunteers to evaluate their physical performance in presence of physical stress demonstrated a significant increase by day 28 in all of the following variables a) distance travelled b) maximum speed c) average speed d) hand grip strength e) maximum oxygen consumption i.e. VO2max (Refer Table 2) Similarly when a dose of $500 \mathrm{mg}$ of Withania somnifera was administered orally to healthy volunteers by day 28, a significant increase was noticed in the following variables such as a) distance travelled b) maximum speed c) average speed d) hand grip strength i.e. muscle power e) maximum oxygen consumption i.e. VO2max (Refer Table 2) Thus Withania somnifera demonstrated a significant increase in all variables used to assess physical performance of healthy volunteers in presence of physical stress.

When both doses of Withania somnifera (330 mg and 500 $\mathrm{mg}$ ) were compared to placebo, Withania somnifera in a dose of $330 \mathrm{mg}$ showed significant increase in distance travelled and average speed on day 28 and Withania somnifera in a dose of $500 \mathrm{mg}$ showed significant increase in distance travelled and average speed on day 14 and day 28. Increase in maximum speed, hand grip strength i.e. muscle power and maximum oxygen consumption $\left(\mathrm{VO}_{2} \max \right)$ were comparable with placebo group, but an increasing trend was seen in magnitude of these variables on day 14 and day 28 in both Withania somnifera $330 \mathrm{mg}$ and $500 \mathrm{mg}$ administered group, which was absent in placebo group. Average speed and distance travelled represents short term aerobic activity, which has shown significant increase compared to placebo in Withania somnifera $330 \mathrm{mg}$ and $500 \mathrm{mg}$ administered healthy volunteers within a one month of drug administration. While long term aerobic endurance parameters like VO2max and muscle power have shown significant increase compared to its baseline values, but not when they were compared to placebo.

Withania somnifera in a dose of $500 \mathrm{mg}$ did demonstrate a significant incremental effect as early as by day 14 while Withania somnifera $330 \mathrm{mg}$ showed significant incremental effect by day 28 and was not evident by day 14. But when Withania somnifera $330 \mathrm{mg}$ dose was compared with Withania somnifera $500 \mathrm{mg}$, we did not find significant increase in dose effect. Both doses of Withania somnifera (330 $\mathrm{mg}$ and $500 \mathrm{mg}$ ) selected between therapeutic range have similar effect on physical performance when exposed to physical stress, and no dose dependant effect was observed. [Refer Table 1 and 2]

Withania somnifera is known as an adaptogen, as it increases resistance of the body to physical, chemical, and biological stress and builds energy and general vitality. ${ }^{16}$ Withania somnifera is prescribed for musculoskeletal problems, described as Mansawardhak. ${ }^{17}$ This effect is attributed to its Ayurvedic properties e.g. ability to provide strength to the muscles, to supply nutrition to the tissues. It is also consider as a rasayana plant. Rasayanas are known to impart strength to the tissues. The 'Balavardhak' action of Ashwagandha can be interpreted as an increase in vigour, vitality, capacity to physical task or at cellular level, imparting strength to cells and tissues. ${ }^{18}$

Similar results were also found in the clinical studies done by Sandhu et al and Raut et al. Sandhu et al in 2010, conducted a clinical study to evaluate the effect of Withania somnifera (500 mg/day) and Terminalia arjuna (500 mg/day) alone and in combination. In this 8 week study on 40 participants, Withania somnifera $(\mathrm{N}=10)$ showed increase in velocity from baseline $5.37 \pm 0.75$ to $5.53 \pm 0.70$, average absolute power from $711.90 \pm 221.62$ to $774.79 \pm 247.42$, average relative power from $11.10 \pm 3.17$ to $12.22 \pm 3.40$ and VO2max from $13.54 \pm 2.46$ to $14.47 \pm 2.28$. In this study, units of any of the variables were not mentioned in the published data and hence we could not directly compare the magnitude of variables between this reference study and the present study variables of physical performance. But the present study and the reference study, both studies have shown the significant increase in physical performance. ${ }^{6}$ Similarly, in another prospective, open-labeled study the doserelated tolerability, safety and activity of increasing doses of Withania somnifera was assessed in healthy adults. Eighteen apparently healthy volunteers were enrolled in the study for 30 days and evaluated for safety and muscle strength on day 10, 20 and 30. Three doses given to each volunteer, which were increased every $10^{\text {th }}$ day. First dose of $750 \mathrm{mg} /$ day was administered orally for first 10 days, followed by $1000 \mathrm{mg} /$ day for next 10 days, and subsequently $1250 \mathrm{mg} /$ day for last 10 days. Results of this study ensured that, Withania somnifera in higher doses from 750 to $1250 \mathrm{mg}$ of aqueous root extracts have no adverse effect on hematological and biochemical organ function safety. There was significant improvement in hand grip strength, which increased from 34.46 \pm 9.96 to $37.23 \pm 11.66$ by day 30 , quadriceps force which change from $28.02 \pm 8.23$ to $34.05 \pm 10.80$ by day 30 , and back extensor force increased from $26.00 \pm 8.83$ to $30.02 \pm 8.10$ by day $30 .{ }^{19}$ In the present study also, after Withania somnifera $330 \mathrm{mg}$ and $500 \mathrm{mg}$ drug administration for 28 day in healthy adult volunteers, we also found the similar increase in the hand grip strength i.e. muscle power. 
Currently there is no clinical data available in which the effect of Withania somnifera on sympathetic nervous system in presence of physical stress has been evaluated. But in clinical studies conducted by Sandhu et al and Raut et al the effect of Withania somnifera on resting blood pressure before and after administration of Withania somnifera in healthy adults was studied. Both the studies showed no change in systolic and diastolic BP and pulse rate compared to day 0 i.e. baseline. In the present study also, there was no statistical change in the resting heart rate measured before starting each exercise protocol on day 0 (baseline), day 14 and day 28 in both Withania somnifera administered group of health volunteers. But systolic BP was decreased statistically in fixed workload test when compared with placebo while cold pressor test there was only decreasing trend. While statistical decrease in diastolic BP (within group) is detected in cold pressor test. WS did demonstrate sympatholytic activity reflecting its antistress actions in fixed workload but similar results were not produced in cold pressor test.

The study did have limitations as it was an open label, pilot study including small number of volunteers and we did not measure the biochemical parameters of stress like blood cortisol level.

To produce more concrete and promising results, there is need to conduct similar kind of studies in large number of healthy adult population by proper sample size calculation for long duration of 3 to 6 months.

\section{CONCLUSION}

In the present study, Withania somnifera in doses of 330 $\mathrm{mg}$ and $500 \mathrm{mg}$, significantly increased the distance travelled and average speed compared to placebo. An increasing trend compared to baseline was observed in muscle power and VO2max after one month of drug administration in healthy individuals in presence of physical stress. WS 330 and 500 groups showed significant decrease in mean systolic BP in fixed workload exercise, compared to placebo reflecting its antistress and adaptogenic effects.

Funding: Diamond Jubilee Society trust of Seth GS Medical College and KEM Hospital, Parel, Mumbai, Maharashtra, India

Conflict of interest: None declared

Ethical approval: The study was approved by the Institutional Ethics Committee

\section{REFERENCES}

1. Mason JW. A historical view of the stress field. J Human Stress. 1975;1:6-12.

2. Keller-Wood M. Hypothalamic-Pituitary-Adrenal Axis-Feedback Control. Compr Physiol. 2015;5:1161-82.
3. Emmons KM, Weidner G. The Effect of Cognitive and Physical Stress on Cardiovascular Reactivity among Smokers and Oral Contraceptive Users. Psychophysiology. 1988;25:166-71.

4. Guyton AC, Hall J. Textbook of Medical Physiology. 11th ed. Philadelphia: Saunders Elsevier; 2006.

5. Allen R. Psychophysiology of the Human Stress Response. University of Maryland, College Park; 1990.

6. Sandhu JS, Shah B, Shenoy S, Chauhan S, Lavekar GS, Padhi MM. Effects of Withaniasomnifera (Ashwagandha) and Terminaliaarjuna (Arjuna) on physical performance and cardiorespiratory endurance in healthy young adults. Int $\mathbf{J}$ Ayurveda Res. 2010;1:144-9.

7. Adedoyin RA, Adeyanju SA, Balogun MO, Akintomide AO, Adebayo RA, Akinwusi PO, Awotidebe TOet al. Assessment of exercise capacity in African patients with chronic heart failure using six minutes walk test. Int J Gen Med. 2010;8:109-13.

8. Díaz O, Morales A, Osses R, Klaassen J, Lisboa C, Saldías F. Six-minute-walk test and maximum exercise test in cycloergometer in chronic obstructive pulmonary disease. Are the physiological demands equivalent? Arch Bronconeumol. 2010;46:294-301.

9. Foster C, Pollock ML, Rod JL, Dymond DS, Wible G, Schmidt DH. Evaluation offunctional capacity during exercise radionuclide angiography. Cardiology. 1983;70:85-93.

10. Lucas C, Stevenson LW, Johnson W, Hartley H, Hamilton MA, Walden J, et al . The 6-min walk and peak oxygen consumption in advanced heart failure: aerobic capacity and survival. Am Heart J. 1999;138:618-24.

11. Innes E. Handgrip strength testing: A review of the literature. AustOccTher J. 1999;46:120-40.

12. Golding LA, Meyers CR, Sinning WE. Y's way to physical fitness: The complete guide to fitness and instruction. Human Kinetics; 3 rd ed. Champaign, IL;1989.

13. Golding L. The "Y's" way to Physical Fitness. Human Kinetics; Champaign, IL; 2000.

14. Arts FJ, Kuipers H, Jeukendrup AE, Saris WH. A short cycle ergometer test to predict maximal workload and maximal oxygen uptake. Int J Sports Med. 1993;14:460-4.

15. Mourot L, Bouhaddi M, Regnard J. Effects of the cold pressor test on cardiac autonomic control in normal subjects. Physiol Res. 2009;58:83-91.

16. David W, Maimes S. Adaptogens. Herbs for Strength, Stamina, and Stress Relief. 1st ed. Rochester Vermont: Healing Arts Press; 2007.

17. Gupta GL, Rana AC. Withania somnifera (Ashwagandha): A Review. Pharmacogn Rev. 2007;1:129-36.

18. Gogte VM. Ayurvedic pharmacology and therapeutic use of medicinal plants (Dravyagunavigyana). 1st ed. Sharp-tm-Dense; 2000;301. 
19. Raut AA, Rege NN, Tadvi FM, Solanki PV, Kene KR, Shirolkar SG, et al. Exploratory study to evaluate tolerability, safety, and activity of
Ashwagandha (Withania somnifera) in healthy volunteers. J Ayurveda Integr Med. 2012;3:111-4.

Cite this article as: Tripathi RK, Salve BA, Petare

AU, Raut AA, Rege NN. Effect of Withania somnifera on physical and cardiovascular performance induced by physical stress in healthy human volunteers. Int J Basic Clin Pharmacol 2016;5:2510-6. 